\title{
IMPROVED EXPANDABLE PROSTHESIS IN POSTPNEUMONECTOMY SYNDROME WITH DEFORMED THORAX
}

Yoshio Tsunezuka, MD, Hideo Sato, MD, Shun-ichi Watanabe, MD, Masaya Tamura, MD, Makoto Tsubota, MD, and Masahiro Seki, MD, Kanazawa, Japan

Postpneumonectomy syndrome is a rare complication of pneumonectomy. The mediastinum, heart, and lung shift into the postoperative thoracic space, and the trachea deviates to the posterior contralaterally after pneumonectomy, causing symptomatic airway compression. Prevention or treatment of postpneumonectomy syndrome with various procedures has been reported. We report the case of a patient in whom the right thorax was deformed and right pneumonectomy was performed because of laceration of the right main bronchus as a result of a traffic accident that led to progressive exertional dyspnea. It was successfully managed with an improved expandable prosthesis.

Clinical summary. A 37-year-old man underwent reconstruction of the right chest wall and trachea and right pneumonectomy for laceration of the right main bronchus as the result of a traffic accident on August 21, 1994. Approximately 1 year later, he complained of exertional dyspnea, an increased cough, and sputum production. Bronchoscopy revealed tracheal stenosis caused by postinflammatory change; there was no stenosis of the left main bronchus, and the right main bronchial stump was clear. A Dumon stent $(16 \mathrm{~mm} \times 70 \mathrm{~mm})$ was positioned in the trachea. Two years after the operation, he experienced frequent pulmonary infections and bronchitis. Computed tomography showed gross herniation of the left lung into the right hemithorax and rightward mediastinal shift with compression of the left main bronchus stretched over the vertebral column and aorta (Fig. 1). Arterial blood gases showed moderate hypoxemia, and pulmonary function tests showed a moderate reduction in pulmonary overdistention (forced vital capacity [FVC] $2.05 \mathrm{~L}$; forced expiratory volume in 1 second/forced vital capacity $\left(\mathrm{FEV}_{1} /\right.$ FVC) ratio, 0.87; peak expiratory flow rate, $3.88 \mathrm{~L} / \mathrm{s}$; maximum mid-expiratory flow rate, $2.39 \mathrm{~L} / \mathrm{s} ; \mathbf{P a c o}_{2}, 51.2$ $\mathrm{mm} \mathrm{Hg} ; \mathrm{PaO}_{2}, 88.8 \mathrm{~mm} \mathrm{Hg}$ ). Analyzing the shape and capacity of the right deformed thorax from 3-dimensional computed tomography, a silicone rubber expandable prosthesis $(820 \mathrm{ml}, 130 \mathrm{~L} \times 190 \mathrm{Wmax} \times 50 \mathrm{~mm} \mathrm{H})$ was made to occupy the intrathoracic space as much as possible

From the Depariment of Thoracic Surgery, Ishikawa Prefectural Central Hospital, Kanazawa, Japan.

Received for publication March 4, 1998; accepted for publication April 9, 1998

Address for reprints: Yoshio Tsunezuka, MD, Department of Thoracic Surgery, Ishikawa Prefectural Central Hospital, 153-Nu, Minamishinbomachi, Kanazawa, 920, Japan;

J Thorac Cardiovasc Surg 1998;116:526-8

Copyright (C) 1998 by Mosby, Inc.

$0022-5223 / 98 \$ 5.00+0 \quad \mathbf{1 2 / 5 4 / 9 0 8 8 5}$
(Koken Corp Ltd, Tokyo, Japan). In the upper space of the right thorax including the deformed area, a dead space was made to prevent damaging the prosthesis by contact with fractured ribs' edges. This silicone prosthesis was an improved tissue expander used in the field of plastic surgery. It consisted of a balloon-like expandable bag, a connecter, and a remote reservoir dome (injection port; Fig. 2).

In May 1997, right thoracotomy with lysing of pleural adhesions was performed; the prosthesis was inserted into the thoracic space and inflated with sterile saline solution to $400 \mathrm{~mL}$. Prophylactic antibiotics against infection were administered before the operation. Six months later, more than $200 \mathrm{~mL}$ of saline solution was added by a 23 -gauge needle through the subcutaneous injection port. Postoperative chest radiographs and computed tomographic scans showed that the mediastinal structure was recentered with relief of the left main bronchial stenosis (Fig. 1). Pulmonary function test did not significantly improve (FVC, $1.95 \mathrm{~L} ; \mathrm{FEV}_{1} / \mathrm{FVC}$ ratio, 0.89; peak expiratory flow rate, $4.81 \mathrm{~L} / \mathrm{s}$; maximal mid-expiratory flow rate, $2.68 \mathrm{~L} / \mathrm{s}$; $\mathrm{PaCO}_{2}, 48.2 \mathrm{~mm} \mathrm{Hg} ; \mathrm{PaO}_{2}, 89.2 \mathrm{~mm} \mathrm{Hg}$ ), but exertional dyspnea disappeared after the operation. The patient has been well 1 year after implantation, and the prosthesis has never leaked.

Discussion. Surgical treatment for pneumonectomy syndrome diminishes the severe mediastinal shift and rotation and corrects the tracheobronchial compression. Various treatments for prevention of this syndrome have been reported. To prevent postpneumonectomy syndrome, it had been reported that a sulfur hexafluoride, SF6, injection into the thoracic cavity was performed after the operation. However, this procedure is not effective to recenter the mediastinum because of the subcutaneous escape of injected gas. ${ }^{1}$ Horvath and colleagues ${ }^{2}$ reported that, in children, the inscrtion of a Dacron graft between the ascending and descending aorta with separation of the aortic arch between the left carotid and subclavian arteries was performed. This bypass procedure is effective to improve compression of the main bronchus adhered to the aortic arch but is invasive. Johnson and colleagues. ${ }^{3}$ used methyl-methacrylate spheres in the thoracic space in 1946, but their spheres occasionally led to tracheal crosion or pseudoaneurysm. Intrathoracic expandable prosthesis was first reported by Rasch and colleagues ${ }^{4}$ in 1990 . The patient was a 5-month-old infant who demonstrated severe respiratory distress after right pneumonectomy for total pulmonary sequestration. Intrathoracic expandable prosthesis has an advantage bccause the volume of the bag can be varied. This advantage is particularly useful in children because the volume can be increased according to growth. Another advantage is that the mediastinum can be recentered slowly and progressively by increasing the 

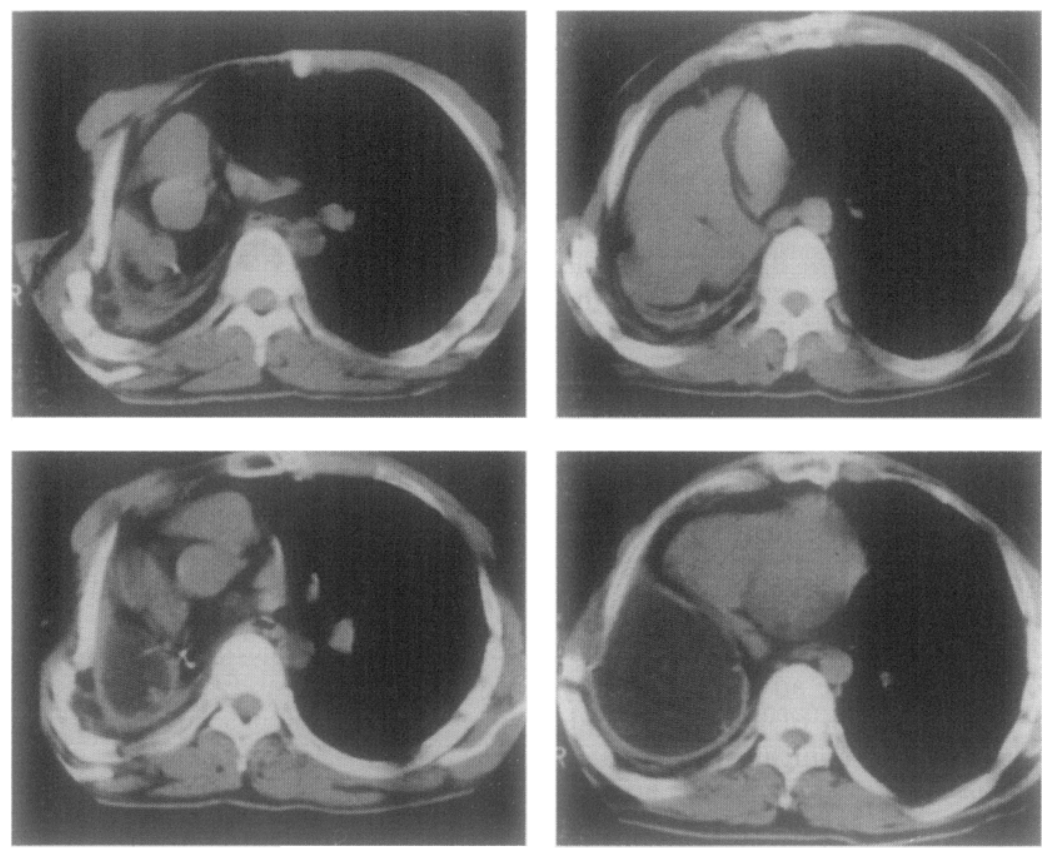

Fig. 1. Computed tomography of the chest after right pneumonectomy: Before (top) and after (bottom) implantation of the prosthesis. Before operation, there is marked mediastinal shift, counterclockwise rotation, and herniation of the left lung. After implantation, the mediastinum was recentered with a prosthesis filled with saline solution.

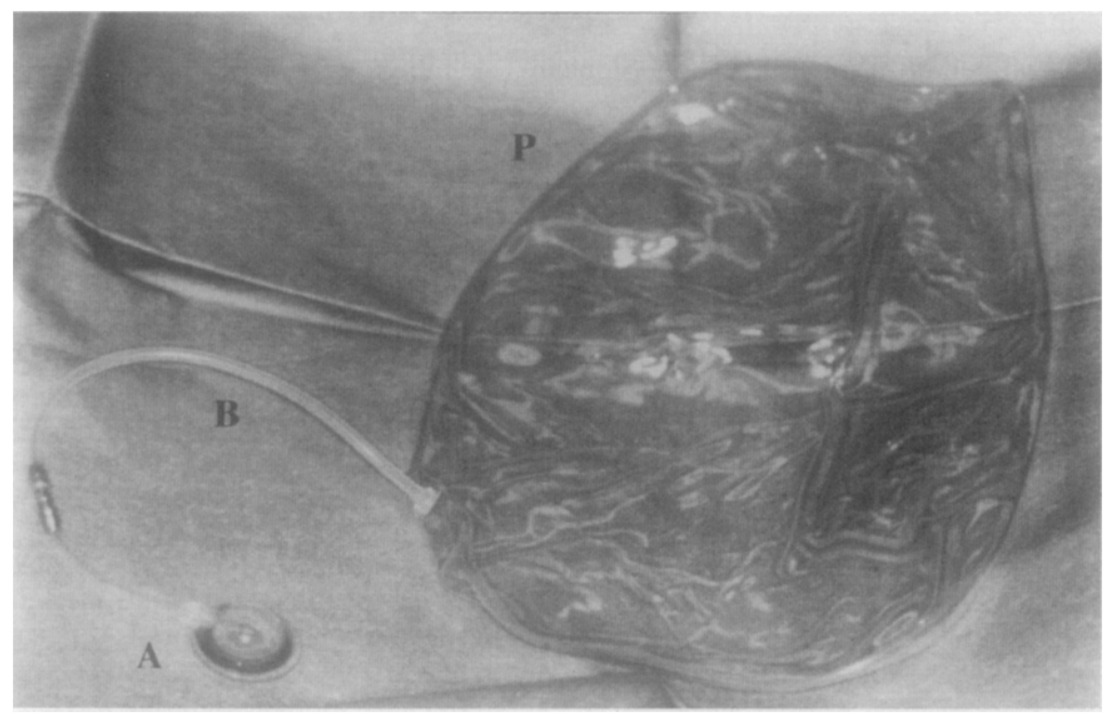

Fig. 2. Photograph of the new expandable prosthesis: $P$, silicone bag prosthesis; $B$, tube and connector; $A$, reservoir dome (injection port).

material volume of the bag, which is useful in postpneumonectomy in adult patients. Our expandable prosthesis is an improved tissue expander used to expand skin and subcutaneous tissue in the plastic surgery field. This expander has an injection port, into which we can inject saline solution in the subcutaneous tissue of the subclavicular region. The tube between the injection port and the silicone bag is laid subcutaneously through the intercostal space from the intrathoracic space. The right thorax of this patient was deformed because of a traffic accident, 
and it was doubtful whether an existing expandable pros thesis could be useful to fill the shape and volume. There was also a risk of damaging the prosthesis by contact with the incised ribs' edges, so we made a specially shaped cxpandable prosthesis without the upper part of the right thorax. The prosthesis was made egg-shell or ball-shaped to equalize the pressure of the internal wall of the silicone bag. Because it is important that the prosthesis not be able to move in the thoracic space and not collapse as the result of a leak caused by overinflation and injury, the shape and volume must be determined carefully. Two cases have been reported in which the prosthesis collapsed because of a leak. One was a valve set-type, and the prosthesis leaked near 1 of the fixation points. ${ }^{5}$ The other was a 5 month-old infant, and the device developed a leak 8 months after the operation. ${ }^{4}$ It may be necessary to improve the intensity of the bag's wall in the future.

In conclusion, our new expandable prosthesis is characterized by the proper thoracic shape, a subcutaneous remote injection port, and the advantage of easy volume management. The insertion of a new expandable prosthesis can improve the clinical symptoms of postpneumoncctomy syndrome, even with a deformed thorax.

\section{REFERENCES}

1. Harada K, Hamaguchi N, Shimada Y, Sayoyama N, Minamimoto $\mathrm{T}$, Inoue $\mathrm{K}$. Use of sulfer hexafluoride, SF6, in the management of the postpneumonectomy pleural space. Respiration 1984;46:201-8.

2. Horvath P, Dinwiddie R, Stark J. Successful surgical treatment of tracheal compression following right pneumonectomy in infancy. Eur J Cardiothorac Surg 1990;4:351-4.

3. Johnson J, Kirby CK, Lazatin CS, Cocke JA. The clinical use of a prosthesis to prevent overdistension of the remaining lung following pneumonectomy. J Thorac Surg 1949;18:164-72.

4. Rasch DK, Grover FL, Schnapf BM, Clarke E, Polard TG. Right pneumonectomy syndrome in infancy treated with an expandable prosthesis. Ann Thorac Surg 190;50:465-6.

5. Audry G, Balquet P, Vazquex MP, Dejerine ES, Baculard A, Boule $M$, et al. Expandable prosthesis in right postpneumonectomy syndrome in childhood and adolescence. Ann Thorac Surg 1993;56:323-7.

\title{
MINIMALLY INVASIVE LEFT ANTERIOR DESCENDING CORONARY ARTERY BYPASS WITH RIGHT GASTROEPIPLOIC ARTERY GRAFT
}

\author{
Toshiya Ohtsuka, MD, Munemoto Endoh, MD, and Shinichi Takamoto, MD, Tokyo, Japan
}

In minimally invasive coronary artery bypass grafting (MICABG) to the left anterior descending artery (LAD) the left internal thoracic artery (LITA) cannot be used in some patients. LITAs have already been used in the most of the redo cases. The harvested LITA grafts may be short or may have insufficient flow for coronary anastomoses. In these circumstances, the right gastroepiploic artery (GEA) can be an alternative graft.

In this communication, we report our clinical experience with MICABG to the LAD with GEA grafts.

Patients. The GEAs were used for MICABG to the LAD in 5 patients. There were 4 redo cases. In 3 of them, the LITAs had already been used for grafting. In 1 redo case, the LITA was left, but the GEA was selected for

From the Department of Cardiothoracic Surgery, University of Tokyo, Tokyo, Japan.

Received for publication April 21, 1998; accepted for publication April 24, 1998.

Address for reprints: Toshiya Ohtsuka, MD, Department of Cardiothoracic Surgery, University of Tokyo, 7-3-1 Hongo, Bunkyo-ku, Tokyo 113, Japan.

J Thorac Cardiovase Surg 1998;116:528-9

Copyright (C) 1998 by Mosby, hnc.

$0022-5223 / 98 \$ 5.00+0 \quad \mathbf{1 2 / 5 4 / 9 1 3 7 3}$ anastomosis to the distal LAD. In 1 primary case, the LITA graft had unsatisfactory flow, and the GEA was usce instcad.

Operation and follow-up. A left small anterior thoracotomy was placed at the anterior fourth or fifth intercostal space, and the LAD was identified. A small median laparotomy was made underneath the xiphoid process, and the GEA was pedicled as far as the pylorus ring with an ultrasonic device, Harmonic Scalpel with LCS (Ethicon Endo-Surgery, Inc., Cincinnati, Ohio). ${ }^{1}$ A small hole was created in the left hemidiaphragm, and the GEA pedicle was advanced to the heart through this hole, passing anterior to the stomach and the left hepatic lobe. Coronary anastomosis to the LAD was performed on the beating heart with a mechanical stabilizer.

In each case, angiography was carried out for the GEA 1 week after surgery, and a transcutancous Doppler graft-flow velocity study was performed at the time of discharge. At the outpatient clinic, this Doppler study was performed 2 weeks after discharge and was repeated every 3 months.

Results. The mean total operation time and GEA harvest time were $145 \pm 35$ minutes and $16 \pm 4$ minutes, respectively. The branches from the GEA and its accompanying vein were divided with excellent hemostasis with only the Harmonic scalpel. Each GEA pedicle reached 